To achieve this end, Hesseling advocates a European doctorate through the revitalization of the traditional academic peregrination which made use of the advantages of different systems. A code of practice should be adopted by the main European universities with, among other things, the abolition of fixed completion periods for doctoral projects, emphasis on interdisciplinary work, freedom for the candidate to select both topic and supervisors (the latter from more than one university), use of external examiners (already the practice in Britain) and publication of the thesis in a major language.

One can readily sympathize with these ideals. But given the increasingly tight and competitive marketplace, and given also the domination of the American system, the need to hold a doctorate as well as a bachelor's and a master's degree is greater than ever. It would therefore seem unrealistic to revert to a system of higher education in which the $\mathrm{PhD}$ is for the relatively few. Furthermore, Hesseling's ideals are to a large extent accommodated, especially in the Anglo-American world, by the network of post-doctoral fellowships which provide an opportunity to elaborate and publish doctoral theses. Many of these fellowships are held in institutes for advanced study with their interdisciplinary and international atmosphere. The Princeton Institute has been replicated, mutatis mutandis, not only in the United States itself but also in Germany, The Netherlands and Scotland. In England, several of the Oxbridge colleges give hospitality to advanced researchers in different disciplines.

Closer examination of these and related questions is obviously needed. Hesseling's book is seriously flawed stylistically there are innumerable mistakes of English usage and unnecessary repetitions of material, and many passages are exasperatingly vague. But he has brought a commendable breadth of approach to his subject, and has provided much food for thought for anyone interested in higher education.

Nicholas A. Rupke, Wolfson College, Oxford, $O X 26 U D, U K$, is a geologist and historian of science and medicine.

\section{Quantum question}

\section{Philip Pearle}

The Shaky Game: Einstein, Realism, and the Quantum Theory. By Arthur Fine. University of Chicago Press: 1986. Pp.179. $\$ 25, £ 21.25$.

EVEN such a loving biographer of Einstein and his physics as Abraham Pais seems embarrassed by Einstein's position on quantum theory. In his book 'Subtle is the Lord', Pais quotes Einstein - "I feel that the real joke that the eternal inventor of enigmas has presented us with has absolutely not been understood as yet" and then remarks, "It is believed by nearly all of us that the joke was understood soon after 1925 . . .". Given this belief, and the spectacular successes of quantum theory which nurture it, it is perhaps not surprising that sympathetic and careful analyses of Einstein's attitude have been lacking.

This lack is quite satisfactorily addressed in five (the second to sixth) of the nine essays which make up this book. The essays, most of which have been previously published, are clear, wellreasoned and appropriate settings for the gems they are studded with, quotes from the Einstein archives at Princeton. The sixth essay, "Einstein's Realism", forms a bridge to a rather different piece of country, three provocative articles on realism which reject both it and antirealism in favour of the author's own position, which he calls the "Natural Ontological Attitude" (NOA).

The second essay, which follows an introductory chapter, attacks the oftenpromulgated view that Einstein's position on quantum theory represented a "kind of scientific senility". After giving ample evidence that Einstein's way of thinking supported Poincaré's admiring assessment of ". . . the facility with which he adapts himself to new concepts. . . . He has not remained attached to classical concepts ...", Fine refreshingly concludes that ". . . it was Bohr not Einstein who felt bound by the classical concepts", and "in the end Einstein was more radical in his thinking.

The third essay details Einstein's route to the conviction that quantum theory is not ". . . in principle capable of producing a complete description of an individual physical system", and culminates in a discussion of the famous Einstein-Podolsky-Rosen paper. For those of us who have secretly never felt fully at ease with the tortuous arguments in that paper, and who have wondered how that master of clarity, Einstein, could have done this to us, Fine brings welcome relief. He shows just how complicated the argument of the paper is, presents evidence that Podolsky wrote it without revision by Einstein and analyses a simpler argument that Einstein sent to Schrödinger in a letter. The fifth essay also concerns letters from Einstein which stimulated Schrödinger while he was writing his famous paper on the cat paradox. This paper showed that quantum theory can predict a state for a cat that is a superposition of cat-alive plus cat-dead, an unrealistic situation for a single cat, thus supporting Einstein's statistical interpretation of quantum theory: "... . the description not of a single system but of an ensemble of systems". How delightful to learn that Einstein himself initiated this paradox, with an example of unstable gunpowder in a quantum state of unexploded plus exploded!

I found essay four on Einstein's statistical interpretation to be rather incomplete. Perhaps because Einstein felt that the de Broglie-Bohm "hidden variable" model is not fundamental enough, no discussion is given of this or the models of Wiener-Siegal or Nelson, which many feel are nice examples of how a statistical interpretation may function. Instead Fine presents some of his own work, a refutation of a model he calls "The Standard Answer" (a sharper earlier refutation due to Kochen and Specker is not mentioned) and a possibly satisfactory "Prism Model" whose similarity to the so-called "loophole" models and vulnerability to experimental refutation is not mentioned (until the last essay).

Einstein's realism is analysed next, understood as a faith, and dubbed "Motivational Realism". Fine shows that Einstein, while driven by a passionate realism, drew back from making logical assertions connecting physics to that reality. Apparently philosophers are not so judiciously reticent, and Fine rebuts both realist and antirealist positions. Instead he opts for NOA, a minimalist position, that accepts the truth of what is useful (for example the electron as a set of working ideas and experimental results) without further interpretation.

The NOA may be adequate for a spectator of the game of physics, but I do not see it as appropriate for a player. Fine tells us that NOA makes it easy to adopt "paradigm shifts", but that is passive behaviour. Physics, the active game of creating beautiful pictures with predictive power, was played so well by Einstein not least because of his realist faith.

Fine rather snidely compares the realist faith to religious faith. In the same vein I would add philosopher's faith (in unexamined axiomatic concepts), for it seems each philosopher is refuted by another on such "religious" grounds. There is nothing wrong with faith: all physicists act on more knowledge than they can prove. But in matters of faith, certainly evidence counts. The creative successes of realists over the centuries justify their leap of faith more than that of most others. And, although one might attribute the success of quantum theory in the past 60 years to nonrealists, in practice they deal with the reality of the concepts they use the way Bohr dealt with a horseshoe. He put one on his cottage door, and said, "No, I don't believe in it, but I understand the good luck comes even if you don't believe".

Philip Pearle is a Professor in the Department of Physics, Hamilton College, Clinton, New York 13323, USA. 